\title{
LA RUTA MILENARIA DEL ATÚN: LECCIONES APRENDIDAS DE UN PRODUCTO TURÍSTICO EXPERIENCIAL EN EL LITORAL GADITANO
}

\author{
1Blanca García Henche \\ Universidad de Alcalá. Facultad de CCEE y Turismo \\ Plaza de la Victoria 2 y 4; 28802 Alcalá de Henares Madrid. 918854233 \\ blanca.garcia@uah.es \\ ${ }^{2}$ Isabel Sánchez Moreno \\ Gestora cultural y Directora del Hotel El Alojado de Velarde. Conil de la Frontera \\ isabelsanmor@gmail.com
}

(Fecha envío: 29/11/17 - Fecha aceptación: 27/05/17)

\section{Resumen}

A medida que el modelo turístico tradicional comienza a saturarse, las Administraciones Públicas y la industria turística buscan alternativas que proporcionen una respuesta a una demanda cada vez más exigente y segmentada, que busca experiencias y vivencias en los destinos turísticos y una experiencia total que incluya ocio, cultura e interacción social.

Los recursos sobre los que se sustenta el turismo están sufriendo una gran transformación ante las nuevas tendencias del mercado turístico en busca de nuevas experiencias en los destinos turísticos. En este contexto, el turismo gastronómico adquiere gran relevancia y los destinos con ofertas experienciales se posicionan como productos turísticos dentro del planteamiento promocional y turístico de los diferentes destinos.

En los últimos años la gastronomía se ha convertido en un elemento indispensable para conocer la cultura y el modo de vida de un territorio al responder a valores clásicos que se asocian a las nuevas tendencias en el turismo: respeto a la cultura y la tradición, vida saludable, autenticidad, sostenibilidad y experiencia.

El presente trabajo analiza cómo, desde el Grupo Desarrollo Pesquero Cádiz-Estrecho, se está diseñando y comercializando un producto turístico experiencial: La Ruta Milenaria del Atún.

El proyecto da un paso más en la creación de productos turísticos relacionados con el mar y la pesca en la zona del litoral gaditano, planteando opciones de turismo alternativo que contribuyen a la desestacionalización, siguiendo los preceptos del turismo sostenible.

El objetivo final de este trabajo es analizar las primeras fases de desarrollo de un nuevo producto en torno a "lo local" como estrategia de desestacionalización de una zona costera española, replicable a otras muchas zonas de la costa española con una alta estacionalidad.

La Ruta Milenaria del Atún se basa en cuatro productos: Raíces (patrimonio/cultura), Sabores (gastronomía), Vida (patrimonio medioambiental) y Emociones (turismo activo). Como actividad de Turismo Pesquero, el proyecto supone la creación de un nuevo producto de turismo alternativo que responde a la creciente demanda de valores ambientales y tradiciones culturales de las zonas costeras. Para ello, se cuenta con una red de empresas que ofrecen actividades muy variadas dentro de un nuevo concepto de turismo multisectorial, sostenible y diferenciado del turismo tradicional de la región.

El marco teórico del trabajo revisa las tendencias del sector turístico hacia el turismo experiencial y la metodología empleada en el estudio es básicamente cualitativa, ya que se ha recurrido a fuentes secundarias, ante todo a la información cualitativa que arrojan el portal de promoción turística de turismo de Cádiz y la Web de la Ruta Milenaria de Atún. Posteriormente, se ha recurrido a fuentes primarias de información, ya que se mantuvieron entrevistas con los responsables del Grupo de Desarrollo Pesquero Cádiz-El Estrecho, coordinador del proyecto, y con las asociaciones y los emprendedores adheridos al proyecto Ruta Milenaria del Atún

El trabajo revela como la zona analizada tiene una excesiva dependencia del turismo de sol y playa en los meses de verano y que el diseño del producto Ruta Milenaria del Atún y su comercialización pueden ayudar a la desestacionalización y al desarrollo sostenible de la zona

\section{Palabras clave}

turismo experiencial, segmentación, sostenibilidad, marketing, Ruta Milenaria del Atún, turismo gastronómico/cultural, desestacionalización

\footnotetext{
1 Doctora en Ciencias de la Dirección, Master Docencia Universitaria y Docente del Área Comercialización e Investigación de Mercados. Uah

2 Isabel Sánchez Moreno. Licenciada en Sociología (UCM) y MBA en Empresas e Instituciones Culturales (Universidad de Salamanca)
} 


\section{Abstract}

As the traditional model of tourism begins to become saturated, Public Administrations and the tourist industry are looking for alternatives that provide a response to an increasingly demanding and segmented, demand that seeks experiences and involvements in tourism destinations and a total experience that includes culture, leisure and social interaction.

Resources on which rests the tourism are suffering a major transformation to the new trends of the tourism market in search of new experiences in tourism destinations. In this context, the culinary tourism acquires great relevance and offering experiential destinations are positioned as tourism products within the tourist and promotional approach to the different destinations.

In recent years the cuisine has become an indispensable to know the culture and the way of life of a territory to respond to classical values that are associated with the new trends in tourism: respect for culture and tradition healthy lifestyle, authenticity, sustainability and experience.

This paper analyzes how, from the Grupo Desarrollo Cádiz-Estrecho, is designing and planning a marketing project for an experiential tourism product: La Ruta Milenaria del Atún.

The project takes a step further in the creation of sea/fishing related tourist project in the coast of Cádiz, while proposing alternative tourism options that contribute to the deseasonalization in accordance with sustainable tourism precepts.

The ultimate goal of this work is to analyze the early stages of developing a new product around "local" as Spanish deseasonalisation of a coastal zone strategy, replicable to other many areas on the Spanish coast with a high seasonality.

The Ruta Milenaria del Atún it is based on four products: Roots (cultural/heritage), Flavors (gastronomy), Life (environmental heritage) and Emotions (active tourism). As tourism fishing activity, the project involves the creation of a new tourism product alternative that responds to the growing demand for environmental values and cultural traditions of the coastal areas. To this end, it boasts a network of companies that offer very varied activities within a new concept of multi-sectoral, sustainable and differentiated from the traditional tourism of the region tourism.

The theoretical framework of work reviews trends in the tourism sector toward experiential tourism and the methodology used in the study is basically qualitative, since it has resorted to secondary sources, primarily on qualitative information that shed the Cadiz Tourism Web and the Ruta Milenaria del Atún. Subsequently, resorted to primary sources of information, since held interviews with the leaders of the Group of fisheries development Cadiz - El Estrecho, responsible for the project, and with associations and entrepreneurs of Ruta Milenaria del Atún

The study reveals how the analyzed area has an excessive dependence on tourism of Sun and beach in the summer months and how the design of the product Ruta Milenaria del Atún and its commercialization helps the out of season demand and the sustainable development of the area

\section{Key Words}

experiential tourism, segmentation, sustainability, marketing, Ruta Milenaria del Atún, gastronomic/cultural tourism, out-of-season

\section{INTRODUCCION}

El objeto de este trabajo es reflexionar sobre los cambios en las tendencias turísticas en busca de experiencias cercanas al entorno local, realizando un análisis del lanzamiento de un nuevo producto turístico cuyo fin es conseguir un desarrollo sostenible a nivel medioambiental, turístico y social gracias a la generación de empleo y a la oferta de productos turísticos desestacionalizadores del sol y playa. Se efectúa, para ello, un análisis de los principales cambios que se han producido en el sector turístico y que propician el lanzamiento de la Ruta Milenaria del Atún de forma conjunta entre la Administración Pública y la iniciativa privada.

El caso de la Ruta Milenaria del Atún sirve para ilustrar una realidad enfocada a las experiencias turísticas, donde el Atún y la cultura en torno al mismo, se convierten en un recurso turístico, es decir, un producto que reivindica la gastronomía local y la autenticidad de las tradiciones locales como recurso turístico.

La Ruta Milenaria del Atún es un proyecto de carácter privado elaborado y promovido por el Grupo de Desarrollo Pesquero Cádiz-Estrecho, desarrollado con apoyos económicos del Fondo Europeo de Pesca (FEP) y de la Consejería de Agricultura, Pesca y Desarrollo Rural de la Junta de Andalucía, en colaboración con asociaciones de empresarios y empresas (más de 100), especialmente relacionadas con el sector turístico, de cada una de las localidades que integran la Ruta Milenaria del Atún: Conil de la Frontera, Barbate, Zahara de los Atunes, Tarifa y La Línea de la Concepción.

El marco teórico del trabajo pone el foco en las tendencias hacia el turismo experiencial. El objetivo final es analizar las primeras fases de desarrollo de un nuevo producto en torno a "lo local" como estrategia de 
desestacionalización de una zona costera española. Para lograr dicho objetivo se ha recurrido a la información cualitativa que arrojan las páginas Web de Turismo de Cádiz y la de la propia Ruta Milenaria del Atún, las redes sociales, artículos en prensa, entrevistas realizadas a responsables del proyecto y a emprendedores que forman parte del mismo, además de la observación no participante. Con todo ello se ha obtenido información del diseño y características del producto y estrategias de comercialización.

El artículo se organiza de la siguiente manera: en primer lugar, se revisa la literatura sobre marketing experiencial. En segundo lugar, se describe la situación de los pueblos de la zona analizada. Seguidamente, se describe el diseño de la Ruta Milenaria del Atún como nuevo producto turístico y su comercialización y se presentan los resultados de la investigación. Finalmente, se elaboran las conclusiones del estudio realizado, donde se demuestra que se ha trabajado especialmente en el diseño de las experiencias, en la implicación de empresas pesqueras y referenciadas con la actividad atunera y en el uso de instrumentos de comunicación con el mercado objetivo.

\section{TURISMO EXPERIENCIAL}

El diseño del producto adecuado es la actividad más importante del marketing. Si no se dispone de un producto turístico que el mercado no desea, ni las mejores campañas promocionales, ni los correctos ajustes de precios, ni la distribución perfecta, conseguirán que los consumidores lo adquieran, al menos de forma repetitiva. Por el contrario, si el producto satisface al consumidor, lo único que se necesita es que el resto de acciones de marketing sean correctas y coherentes para garantizarnos el éxito en el mercado (Serra, 2011).

Los cambios en el comportamiento y en los valores de los consumidores constituyen un factor crítico en el nuevo turismo (Kotler, 2018, 2008). A medida que el modelo tradicional de desarrollo turístico comienza a saturarse, las Administraciones Públicas y la propia industria turística deben buscar alternativas que proporcionen una respuesta a una demanda cada vez más exigente y segmentada (De la Ballina, 2017) y que busca experiencias en los destinos turísticos.

Desde los años 80 los estudios de comportamiento de consumidor comienzan a dar importancia a la parte simbólica y emocional del mismo. Es en esta época cuando se inicia el desarrollo de teorías encaminadas a potenciar la vivencia de experiencias.

El estudio del marketing experiencial es más bien reciente y académicamente está en pleno desarrollo. El marketing experiencial busca inmiscuir directamente al consumidor con el producto, mediante los sentidos, intentando crear en él sentimientos y emociones con el fin de generar experiencias positivas para el cliente hacia el producto o servicio (Moral y Alles, 2012). El objetivo del marketing de experiencias es transformar a los clientes del producto en seguidores del mismo (Barkoza, 2013), entendiendo la lógica de las experiencias memorables para el consumidor y gestionarlas adecuadamente (Jesen, 1999).

Ese consumidor experiencial no se escapa al sector turístico. El turismo experiencial se ha convertido en la tendencia del presente en el sector, donde la experiencia es objeto esencial del viaje y el cliente siente cada vez más la necesidad de experimentar un destino para optimizar su vivencia del mismo. Al integrar aspectos como la cultura y las tradiciones de las gentes del lugar, el turista se siente inmerso en su forma de vida local y obtiene una imagen positiva del destino visitado.

Según Schmitt (2003), uno de los primeros autores en acuñar el término Marketing Experiencial, existen cinco formas de promover la experiencia del consumidor: (1) A través de la experiencia sensorial (Sense); (2) A través de la experiencia emocional (Feel); (3) A través de la experiencia física o estilo de vida (Act); (4) A través de la experiencia cognitiva y creativa (Think) y (5) A través de la experiencia de identidad social (Relate).

La comprensión de la experiencia turística, en su dimensión sensorial, es relevante para la optimización de los destinos turísticos. En consecuencia, se han de desarrollar productos innovadores y experiencias que dejen una marca positiva para quien visita el destino, además de contribuir positivamente a la calidad de vida de la población local (Agapito, Mendes y Valle, 2013, 2014; Kastenholz, Carneiro y Marques, 2012).

Algunos estudios empíricos desarrollados en el sector turístico (Ballantyne, Parker y Sutherland, 2011; Hosany y Witham, 2010; Kastenholz et al., 2012; Morgan y Xu, 2009) sugieren que la experiencia sensorial es muy relevante para obtener experiencias turísticas satisfactorias. Sin embargo, son pocos los estudios que analizan la experiencia sensorial en las áreas hasta ahora dedicadas al turismo de sol y playa y, menos aún, en referencia a las actividades de ocio cultural y gastronómico como recurso de turismo experiencial.

La economía de la experiencia (Pine y Gilmore, 1998) lleva a los destinos a convertirse en escenarios en los que se crean experiencias. En esta economía de la experiencia, la cultura se convierte en una materia prima esencial y el turismo cultural y gastronómico es un elemento cada vez más importante. 
En los últimos años la gastronomía se ha convertido en un elemento indispensable para conocer la cultura y el modo de vida de un territorio al responder a valores clásicos que se asocian a las nuevas tendencias en el turismo: respeto a la cultura y la tradición, vida saludable, autenticidad, sostenibilidad y experiencia (OMT, 2012). La degustación de productos gastronómicos puede ser un ejemplo de la interacción entre el turista y la cultura local. Así la gastronomía, los estilos de vida de consumo de alimentos, se pueden entender como un atractivo turístico (Mascarenhas y Gândara, 2010) y la creación del producto Ruta Milenaria del Atún, reúne la mayoría de esas variables anteriormente citadas como recursos culturales.

Shedroff (2001) afirmaba que existen turistas que viajan para vivir experiencias únicas. Por su parte, Richards (2004) considera que el turismo cultural está convirtiéndose en un producto de vivencia. Así, muchos consumidores buscan, lo local y la vida cotidiana como algo auténtico (Richards,2011).

Según un estudio sobre los perfiles turísticos en función de las motivaciones para viajar (Beltran y Parra, 2017), los perfiles cada vez más frecuentes son los viajeros antropológicos, emocionales y hedonistas.

Un $85 \%$ de los menores de 35 años consideran que "experimentar lo local" es una de sus principales razones para viajar (WYSE Travel Confederation, 2015).

Según Hinojosa (2016) una de las principales tendencias a tener en cuenta en el sector turístico a partir de 2017 es ofrecer experiencias más personalizadas en hoteles y planificación de viajes, ya que los turistas buscan productos turísticos poco explotados y que resalten la vivencia de experiencias novedosas (Castaño, 2015).

En definitiva, en la economía de la experiencia, el sector turístico ha de enfocarse a este segmento de viajeros para los cuales lo esencial es tener vivencias y emociones acordes con su estilo de vida. En el caso del caso de la Ruta Milenaria del Atún, el turismo gastronómico y cultural en torno al atún, puede suponer un recurso básico para ese turismo experiencial en la provincia de Cádiz y, en concreto, en la Comarca de La Janda, donde se centra el caso de estudio de este trabajo.

\section{METODOLOGIA}

El objetivo final de este trabajo es analizar las primeras fases de desarrollo de un nuevo producto en torno a "lo local" como estrategia de desestacionalización de una zona costera española, replicable a otras muchas zonas de la costa española con una alta estacionalidad.

Secuencialmente la obtención de los datos siguió la siguiente planificación:

- En primer lugar, se realizó una revisión de fuentes secundarias sobre el turismo experiencial.

- En segundo lugar, se utilizaron fuentes secundarias para conocer la situación del turismo en la zona de la comarca de La Janda y el Estrecho, para obtener información sobre las características de la demanda turística y oferta hotelera (ocupación y establecimientos abiertos).

- Con dichos datos se realizan las entrevistas abiertas con los informantes clave del Grupo de Desarrollo Pesquero Cádiz-Estrecho, Asociaciones y emprendedores adheridos al proyecto. Concretamente se realizaron entrevistas con el Presidente del Grupo de Desarrollo, Nicolás Fernández y con la técnico del mismo, con el Patronato de Turismo de Conil de la Frontera (Concejala de Turismo), con el presidente de la Asociación de Empresarios Turísticos de Conil de la Frontera y con emprendedores de empresas relacionadas con el turismo y la gastronomía (Agencia de Viajes La Janda, Empresa de productos pesqueros Petaca Chico, Hotel El Alojado de Velarde y restaurantes Feduchi y La Mejorana de Conil de la Frontera), durante los meses de enero a marzo de 2016

Los temas abordados fueron los objetivos, actividades y acciones comerciales del Proyecto y retos gerenciales del mismo, centrados en combatir la estacionalidad a través de la transversalidad, complementariedad y cooperación (sinergias) entre segmentos, empresas, productos y territorios. Se ha utilizado el enfoque desarrollado por Cross y Parker (2004), que busca comprender la articulación de los pequeños negocios y las redes de emprendedores y en qué medida la colaboración entre ellos con el Grupo de Desarrollo permite el diseño y comercialización exitoso del proyecto Ruta Milenaria del Atún. Concretamente, el proyecto pretende reducir la excesiva concentración temporal de los flujos turísticos y convertir el producto Ruta Milenaria del Atún, en un destino de referencia también fuera de temporada. Con las ideas recurrentes en las entrevistas y la información obtenida de las fuentes secundarias, se ha desarrollado un análisis basado en tres fases: (1) justificación del proyecto, (2) desarrollo del mismo a través de experiencias turísticas con cuatro enfoques (Raíces, Sabores, Vida y Emociones) y (3) comercialización.

- Se obtuvieron datos por observación, con presencia en algunos de los eventos organizados para la presentación de la Ruta Milenaria del Atún en Fitur, presentación de diferentes Jornadas Gastronómicas y presentación del producto a los medios de comunicación.

- Finalmente se han revisado y analizado las páginas Web de promoción turística de la provincia de Cádiz, la Web del Gobierno de Andalucía y del Instituto Nacional de Estadística y el sitio Web oficial y las redes sociales del producto Ruta Milenaria del Atún. 
Los datos de la investigación primaria y secundaria se han analizado e interpretado lo que ha permitido elaborar un diagnóstico del diseño del producto, Ruta Milenaria del Atún, en sus primeras fases de ciclo de vida como producto turístico.

\section{PROYECTO RUTA MILENARIA DEL ATÚN}

\subsection{Estacionalización en los pueblos que integran La Ruta Milenaria del Atún}

El ámbito de actuación de la Ruta Milenaria del Atún comprende los municipios de occidente a oriente de: Conil de la Frontera, Barbate, Zahara de los Atunes (perteneciente a Barbate) y Tarifa.

Los flujos turísticos que recibe el litoral no se distribuyen de forma homogénea, sino que los mayores volúmenes de turistas se suelen concentrar en los meses cuya climatología es más favorable.

Son muchas las causas que subyacen al fenómeno de la estacionalidad, entre las principales destacan la climatología, la distribución del tiempo de ocio y trabajo, así como de las vacaciones escolares y las características de los productos y servicios ofertados por el destino.

Como se aprecia en la tabla 1 , en el litoral de la Janda es tradicional que durante los meses de junio a septiembre se reciban entre el $40-45 \%$ de visitantes anuales. Durante marzo, abril y mayo se alcanzan cuotas de entre el $25 \%-27 \%$ de visitas mientras que las visitas del primer y del cuarto trimestre oscilan entre el $5 \%-8 \%$.

\begin{tabular}{|c|c|c|c|c|c|c|c|c|c|c|c|c|c|}
\hline Unidades & Total & Enero & Febr. & Mar. & Abril & Mayo & Junio & Julio & Ago. & Sept. & Oct. & No. & Di. \\
\hline Barbate & 59.488 &.. &.. &.. & 3.866 & 6.527 & 8.979 & 13.819 & 12.907 & 9.567 & 2.250 &.. &.. \\
\hline $\begin{array}{c}\text { Conil de } \\
\text { la } \\
\text { Frontera }\end{array}$ & 169.293 &.. &.. &.. & 13.420 & 22.611 & 25.377 & 28.801 & 28.807 & 20.233 & 15.427 &.. &.. \\
\hline Tarifa & 114.158 &.. &.. &.. & 6.242 & 9.935 & 13.258 & 18.966 & 22.545 & 17.248 & 10.783 &.. &.. \\
\hline
\end{tabular}

Tabla 1: Viajeros por puntos turísticos y meses 2014

Fuente: Instituto Nacional de Estadística

Notas: El símbolo .. indica dato no significativo

El gráfico 1, por su parte, muestra los niveles de concentración de visitantes en los meses de verano.

\begin{tabular}{|l|l|l|l|}
\hline Barbate $^{*}$ & Conil de la Frontera & Tarifa \\
\hline & & & \\
\hline
\end{tabular}

Gráfico1: Ocupación hotelera 2014

Fuente: Instituto Nacional de Estadística

*Zahara de los Atunes administrativamente pertenece a Barbate

El fenómeno de cierre temporal de establecimientos hoteleros y en consecuencia de pérdida de empleo es muy fuerte en el litoral de la comarca de la Janda.

Este proceso es muy grave pues supone un lastre para el crecimiento turístico en temporada baja al existir un menor esfuerzo también de promoción y comercialización de las empresas turísticas en atraer clientes.

La estacionalidad de la demanda turística tal y como representan los datos, lleva aparejada una pérdida de rentabilidad de las explotaciones hoteleras $y$, en consecuencia, un mayor número de establecimientos que cierran en temporada baja (Véase tabla 2). 


\begin{tabular}{|c|c|c|c|c|c|c|c|c|c|c|c|c|}
\hline Unidades & Enero & Febrero & Marzo & Abril & Mayo & Junio & Julio & Agosto & Sept. & Oct. & Nov. & Diciem. \\
\hline Barbate & & & & 32 & 33 & 34 & 43 & 43 & 37 & 20 &.. &.. \\
\hline $\begin{array}{c}\text { Conil de } \\
\text { la } \\
\text { Frontera }\end{array}$ & & & & 34 & 45 & 57 & 57 & 57 & 56 & 25 &.. &.. \\
\hline Tarifa & & & & 49 & 46 & 46 & 46 & 47 & 44 & 45 & & \\
\hline
\end{tabular}

Tabla 2: Establecimientos abiertos estimados por puntos turísticos y meses 2014 Fuente: Instituto Nacional de Estadística

Las localidades analizadas son estacionales en términos de empleo y oferta hotelera. Por ello, se muestra una tendencia generalizada al cierre en temporada baja de un amplio número de hoteles.

La concentración de la demanda turística en determinadas épocas del año induce graves distorsiones económicas y sociales, que provocan resultados negativos en la comarca.

La estacionalidad provoca desajustes temporales entre oferta y demanda turística, lo que trae consigo la creación de empleos inestables, problemas de rentabilidad, masificación y/o baja utilización.

Dados los efectos provocados por la estacionalidad, ésta no sólo debe combatirse consiguiendo unos mayores niveles de demanda para la temporada baja, sino tratando de obtener una mejor redistribución de los flujos turísticos a lo largo del año, de forma que se reduzca la presión que se produce sobre las personas y el medio durante la temporada alta.

En este sentido, el proyecto Ruta Milenaria del Atún, sigue la línea de trabajo trazada por el IV Pacto Andaluz por el Turismo, que plantea entre sus objetivos "contribuir a la desestacionalización en el ámbito turístico, y con ello favorecer la optimización de las infraestructuras, servicios, instalaciones y establecimientos turísticos, la mejora de la percepción de la calidad turística y de los beneficios sociales y económicos de su actividad productiva y la descongestión de los destinos turísticos maduros".

Así, La Ruta Milenaria del Atún, se integra como proyecto dentro de las políticas y voluntad por parte de las instituciones y administraciones en la búsqueda de modelos y de programas turísticos que fomenten y aporten soluciones a la estacionalización turística de esta comarca del litoral andaluz.

La Ruta Milenaria del Atún, a través de la transversalidad, complementariedad y cooperación (sinergias) entre segmentos, empresas, productos y territorios tiene entre sus objetivos combatir la estacionalidad turística. Para ello, se han establecido las siguientes metas:

- Convertir el destino Ruta Milenaria del Atún, en un destino de referencia también fuera de temporada.

- Reducir la excesiva concentración temporal de los flujos turísticos. Fomentando una temporada media estable a lo largo del año.

- Atraer a nuevos segmentos de demanda menos estacionales de mercados tradicionales y emergentes.

- Fomentar y promover programas de turismo de calidad a nivel europeo, nacional y regional.

\subsection{Justificación del proyecto}

El objetivo del proyecto Ruta Milenaria del Atún es conseguir un desarrollo sostenible de la región a nivel medioambiental, turístico y social gracias a la generación de empleo y a la oferta de productos turísticos desestacionalizadores del sol y playa en estos pueblos marineros.

Parte de los esfuerzos se centran en una estrategia común en torno a la gastronomía y a actividades relacionadas con la pesca del atún, para aumentar la llegada de visitantes en los meses fuera de la temporada de verano. Se consigue, así, la sostenibilidad del empleo a lo largo del año y la sostenibilidad ambiental y social que supone el mantenimiento de las tradiciones en torno al atún.

El proyecto, por tanto, presenta una oferta multisectorial, sostenible y diferenciada de las concepciones tradicionales del turismo de la región (Véase tabla 3 que recoge las características generales del proyecto).

Siguiendo los preceptos del turismo sostenible, se plantean opciones de turismo alternativo y atractivo que contribuyan a la desestacionalización turística de la comarca, con el objeto de apoyar y complementar la actividad económica del sector pesquero de la zona, con el fin de generar empleo y lograr el desarrollo sostenible de la región, consiguiendo, así, diversificar la oferta turística. 


\begin{tabular}{|c|c|}
\hline LINEA.DE·INTERVENCIÓNa & 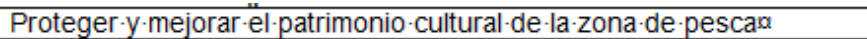 \\
\hline GRUPO·DE·INTERVENCIONa & 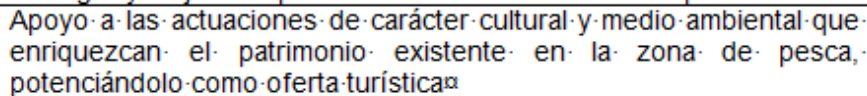 \\
\hline DESTINATARIO & Sector-cultural-y-sector-turísticox \\
\hline PROYECTO & 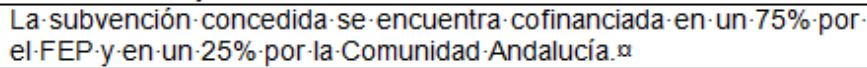 \\
\hline GRUPO-DE.DESARROLLO & Cádiz'el-Estrecho'a \\
\hline DESCRIPCIÓN·DEL·PROYECTO $a$ & Planificación·y·promoción·del·proyecto·'La·Ruta·Milenaria·del·Atún'a \\
\hline LOCALIZACIÓNa & Barbate, Conil, de la·Frontera - Línea de la·Concepcióna \\
\hline LIINEA.DE·INTERVENCIÓNa & 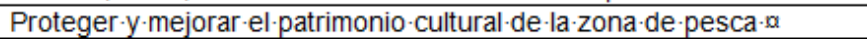 \\
\hline GRUPO-DE.INTERVENCIONa & 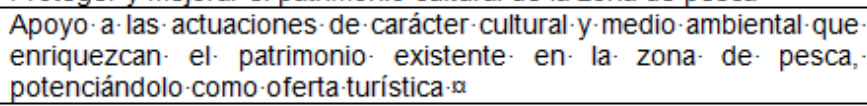 \\
\hline $\begin{array}{l}\text { DESTINATARIO·DE.LA. } \\
\text { OPERACIÓNa }\end{array}$ & Sector $\cdot$ cultural-y·sector-turísticox \\
\hline BENEFICIARIO $\alpha$ & Grupo-de-Desarrollo·Pesquero.Cádiz-Estrechoa \\
\hline $\begin{array}{l}\text { ACUERDO·ADOPTADO·POR·EL } \\
\text { GRUPO } \alpha\end{array}$ & $11 / 07 / 2012^{a} a$ \\
\hline CERTIFICADO-DEL ACUERDO $a$ & $20 / 07 / 2012 \cdot a$ \\
\hline PLAZO·DE·EJECUCIÓNa & $30 / 04 / 2014 a$ \\
\hline $\begin{array}{l}\text { COSTE-TOTAL: } \\
\text { SUBVENCIONABLE }(€): \alpha\end{array}$ & $390.141,65 a$ \\
\hline SUBVENCIÓN·CONCEDIDA(€) $a$ & $390.141,65 a$ \\
\hline INTENSIDAD·DE.LA.AYUDA(\%) $a$ & $100 \% a$ \\
\hline
\end{tabular}

Tabla 3: Características generales del proyecto La Ruta Milenaria del Atún Fuente: http://gdpcadizestrecho.blogspot.com.es/

El proyecto ofrece múltiples opciones agrupadas en distintos paquetes turísticos de forma que cada turista pueda conformar el viaje o su estancia adecuándose a su interés. La Ruta Milenaria del Atún se crea en base a cuatro líneas de actividades basadas en la oferta de experiencias turísticas diseñadas para los diferentes mercados objetivo:

- Raíces, que engloba al patrimonio, la cultura y las tradiciones de la región. Se han preparado una serie de itinerarios que dan a conocer la historia de estas localidades (Barbate y Zahara Atunera, Tarifa de las dos culturas, Los siglos de oro de Conil y Joyas Históricas de la zona).

- Sabores, con diferentes rutas gastronómicas de las localidades implicadas conjugando el pescado, la carne y la verdura de la huerta de la Janda.

- Vida: dirigido a los amantes de la naturaleza. Se da a conocer el entorno natural del litoral de la Janda: Sol y Playa, Parques Naturales, Joyas de la Naturaleza (como las Dunas de Bolonia), Birdwatching (la costa de Trafalgar es un enclave estratégico en el paso migratorio de las aves entre Europa y África) y Whalewatching (avistamiento de cetáceos en el paso del Estrecho de Gibraltar).

- Emociones, que se centra en turismo activo por tierra, mar y aire.

\section{RESULTADOS}

Las nuevas tendencias en la industria han propiciado la aparición y el crecimiento de la oferta de turismo de experiencias. El desarrollo y comercialización de un nuevo proyecto turístico en una zona geográfica única, por su clima y sus tradiciones locales, que atrae turistas, requiere de una serie de actividades y estrategias de marketing experiencial.

El diseño de la oferta y comercialización de la Ruta Milenaria del Atún supone una adaptación y remodelación del litoral de la comarca de La Janda y el Estrecho, ofertando nuevas experiencias a los turistas y a todo ello ha contribuido el asociacionismo del pequeño comercio emprendedor de la zona ((alojamientos, restauración, deporte, actividades de ocio, ...), junto con instituciones públicas en la creación de un producto y marca turística en torno al atún (historia, gastronomía, tradiciones, medio natural, etc.)

\subsection{La Ruta Milenaria del Atún: una respuesta a la búsqueda de nuevas experiencias por parte de los turistas}

Los profesionales del turismo aventuran un panorama de cambios en el sector, principalmente basados en un mayor número de desplazamientos y un aumento del número de escapadas más cortas durante todo el año. Los viajes serán más a la carta, individualizados y ajustados a los gustos del cliente.

Desde el Grupo de Desarrollo Pesquero Cádiz-Estrecho se ha considerado oportuno desarrollar, al igual que algunos destinos competidores, estrategias novedosas de comercialización fundamentadas precisamente en una segmentación del público objetivo, que permitan facilitar la adecuación de la oferta de servicios del destino turístico al cliente, junto con una especialización y consiguiente diferenciación de los competidores tradicionales y 
emergentes. Todo ello redundaría en el desarrollo de una imagen del Turismo en Cádiz acorde a las nuevas necesidades y deseos del cliente.

El nuevo escenario turístico se caracteriza por ser más dinámico y competitivo y por la proliferación de multitud de ofertas especializadas a costes decrecientes. Esto exige a los destinos y las empresas turísticas una atención continua a su propia oferta y a la demanda de los clientes, así como al comportamiento de los competidores y del entorno en general, de manera que sean capaces de responder rápidamente ante los cambios que se producen. La oferta turística actual está viviendo una gran transformación. La experiencia se ha convertido en objeto esencial del viaje y el cliente siente cada vez más la necesidad de experimentar un destino para optimizar su vivencia del mismo.

En este contexto, se ha estimado conveniente la creación de un nuevo producto turístico, La Ruta Milenaria del Atún, que se adapte a las nuevas exigencias de experiencias turísticas por parte de la demanda turística.

Según las últimas tendencias de la demanda, los denominados "turistas de última o tercera generación" aprovechan su estancia en los destinos para buscar experiencias enriquecedoras y vivencias únicas. Así, se pasa de un turista pasivo, mero espectador a un turista activo, que en lugar de "observar" se desplaza al destino para "hacer" algo, involucrándose más en la cultura local.

La experiencia es objeto esencial del viaje para una gran parte de los viajeros actuales. Ya no es suficiente ofrecer tranquilidad, un entorno natural, una gran cantidad de recursos turísticos o la belleza del lugar. A todo eso, ahora hay que añadirle experiencias, es decir, un contacto más intenso y auténtico con sus habitantes, innovación, autenticidad, sorpresa, historias y vivencias y emociones.

Las cuatro líneas de actividad de la Ruta Milenaria del Atún están basadas básicamente en valores intangibles, como las tradiciones (Raíces), la gastronomía (Sabores), el aprovechamiento del patrimonio medioambiental (Vida) y el turismo activo por tierra, mar y aire (Emociones), ofreciendo así un producto turístico experiencial.

Richards (2004) afirma que el turismo cultural está convirtiéndose en un producto de vivencia en el que la visita se juzga en función de todas las características del lugar y no solo por su valor cultural. Así, el patrimonio cultural intangible se convierte en un recurso clave de diferenciación de los destinos turísticos y la zona de la Ruta Milenaria del Atún, en este sentido, además de patrimonio material (museos, iglesias, edificios emblemáticos...), posee una gran y diversa oferta gastronómica y de tradiciones para poner en valor, mostrando el estilo de vida local.

En esa búsqueda de experiencias, en La Ruta Milenaria del Atún, el viajero podrá vivir experiencias únicas como la visita a las almadrabas atuneras, degustar productos derivados del atún (Véase Caso 1), conocer empresas conserveras de atún y el proceso de industrialización artesanal del mismo (Véase Caso 2), visitar el Museo del Atún o realizar cursos de cocina tradicional (Véase Caso 3).

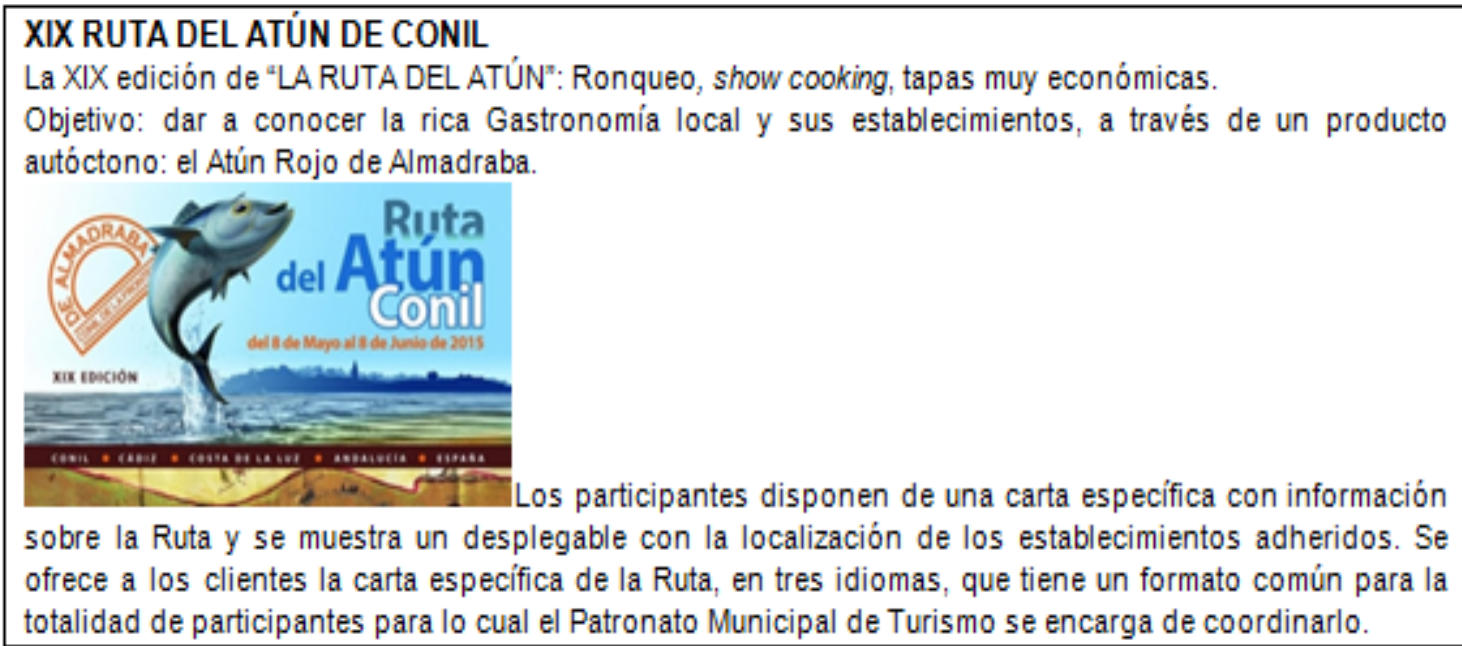

Caso 1: Ruta del Atún. Evento organizado por Conil de la Frontera (2015)

Fuente: http://www. guiadecadiz.com/es/agenda/mayo/2015/xix-ruta-del-atun-conil 


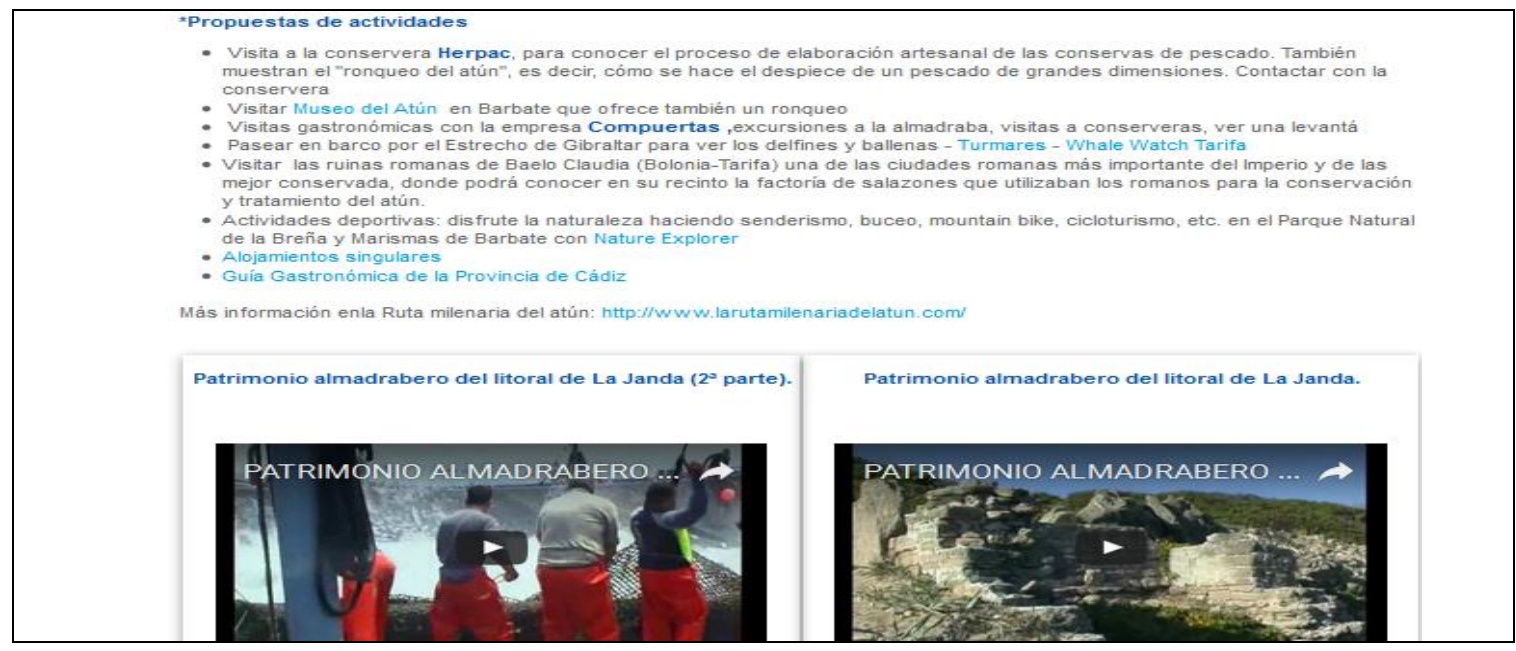

Caso 2: Paquetes de actividades ofertados en La Ruta Milenaria del Atún Fuente: http://www. cadizturismo.com/gastronomia/rutas-gastronomicas/

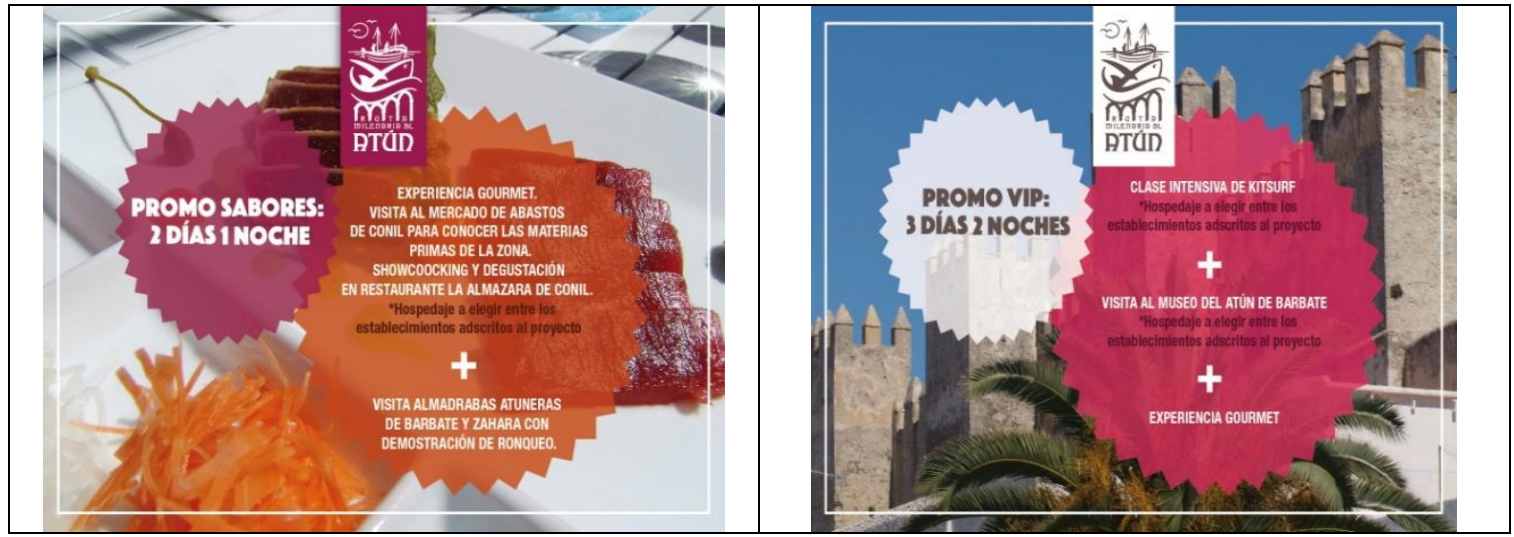

Caso 3: Ejemplo de promociones de ventas organizadas en la web oficial con actividades específicas de turismo experiencial Fuente: www.larutamilenariadelatun.com

En definitiva, los actuales viajeros, consideran las experiencias culinarias como un elemento clave a la hora de elegir el destino. Esa búsqueda de lo local lleva a los turistas a interesarse por la gastronomía local y la cultura en torno al atún y la pesca, donde se puede percibir la idiosincrasia de la gente local, sus hábitos alimenticios, el estilo de vida, los gustos y costumbres gastronómicas, etc.

\subsection{Comercialización de la Ruta Milenaria del Atún}

El ciclo de vida de un producto turístico constituye uno de los temas de mayor relevancia en los análisis de competitividad turística, ya que muestra la evolución del producto en en el tiempo y ayuda a identificar la estrategia comercial más coherente a llevar a cabo (García, Reinares, Armelini, 2013).

El modelo de CVDT de Butler se fundamenta en la Teoría del Ciclo de Vida del producto propuesta por Dean (1950) en el ámbito de gestión del Marketing, adaptándola a los destinos turísticos como si de un producto se tratase, y teniendo en cuenta dimensiones relacionadas con las infraestructuras, actitudes de los turistas y residentes, implicación de agentes locales y externos en la comercialización del producto, accesibilidad a los destinos y competencia de los mismos, tal como recogen estudios de Bigné, Font y Andreu (2000).

Según los estudios de Butler (1980, 2004), las fases que atraviesa un destino son: exploración, implicación, desarrollo, consolidación, estancamiento y declive. Cada etapa presenta una serie de rasgos característicos en cuanto a la situación de la demanda, la oferta, la comercialización y la competencia (Kotler, 2018; De la Ballina, 2017; Rey, 2017).

La explicación del desarrollo de los destinos turísticos proporcionada por el ciclo de vida, puede emplearse como criterio para la valoración de las diferentes opciones estratégicas, con el fin de aprovechar las oportunidades que en cada caso presenta el mercado, sin embargo, no proporciona pautas de actuación (Camisón,1989), 
La Ruta Milenaria del Atún, es un producto en las primeras fases de su ciclo de vida, por lo que el diseño del producto y la promoción del mismo son las estrategias en las que se ha de enfocar la comercialización.

El producto surgió en el año 2013 como iniciativa del Grupo de Desarrollo Pesquero Cádiz-Estrecho y de otras empresas relacionadas con la actividad pesquera y turística de la zona. Desde diciembre de 2015, la gestión del proyecto pasa a manos de la Asociación de empresarios Ruta Milenaria del Atún.

La implicación de los agentes locales y muchas de las infraestructuras necesarias para el diseño de la ruta se han desarrollado de forma rápida, ya que el destino está suficientemente desarrollado en referencia al producto "sol y playa". No obstante, se ha trabajado en el diseño de las experiencias específicas de la ruta, en la implicación de empresas pesqueras y referenciadas con la actividad atunera y en el uso de instrumentos de comunicación con el mercado objetivo.

Desde el Grupo de Desarrollo se han llevado a cabo diferentes acciones de marketing y difusión, con la intención de dar a conocer el proyecto, como la presentación oficial en Fitur 2015, diferentes estrategias de difusión on line (creación de Web y perfiles en redes sociales), viajes de familiarización, asistencia a ferias turísticas y distintas estrategias de relaciones públicas con variados medios de comunicación (Véase Caso 4, que recoge algunas de esas acciones de comunicación).

Respecto al uso de los instrumentos de comunicación on line, se ha de tener en cuenta que el desarrollo de Internet ha revolucionado la forma de operar de la industria turística (Theodosiou y Katsikea, 2012).

La búsqueda de información es una parte importante del proceso de decisión de compra que ha evolucionado sustancialmente gracias a Internet y las TICS, ya que reducen la incertidumbre (Grezzel y Yoo, 2008; Mackay y Vogt, 2012). Los nuevos canales de comunicación generados por la categoría de Web 2.0 y 3.0 han ampliado el sentido de las comunicaciones (García, 2011, 2016), ya que el contenido de las páginas puede ser elaborado por la propia empresa y por la información aportada por los usuarios, bloggers o intagrammers, lo que fomenta la interacción, participación y creación de redes sociales o comunidades (O'Reilly, 2007) y la Ruta Milenaria del Atún, tiene estas premisas presentes a la hora de comunicar al mercado la existencia de su producto.

Así, la Ruta Milenaria del Atún creó desde el inicio un sitio Web oficial (Véase Caso 5) con información de los productos ofertados y los paquetes diseñados dentro de las cuatro experiencias turísticas (Raíces, Sabores, Vida y Emociones) y el Patronato Provincial de Turismo de Cádiz, en su Web Oficial promociona, asimismo, La Ruta Milenaria del Atún.

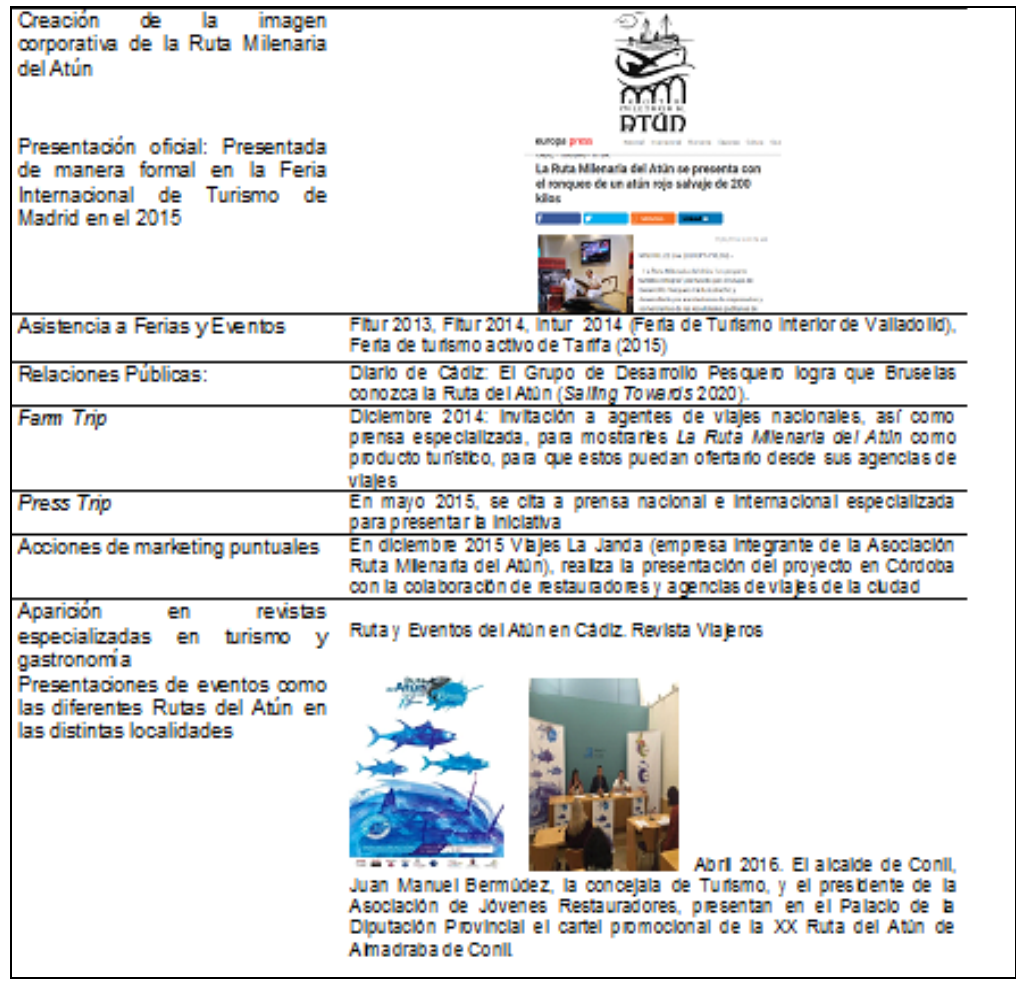

Caso 4: Estrategias de comunicación de la Ruta Milenaria del Atún

Fuente: www.larutamilenariadelatun.com; http://www.europapress.es/andalucia/turismo-00476/noticia-cadiz-turismo-fitur-rutamilenaria-atun-presenta-ronqueo-atun-rojo-salvaje-200-kilos-20140122161824.html; www.diariodecadiz.es; http://www.diariodecadiz.es/article/provincia/1910381/la/ruta/milenaria/atun/se/promociona/intur/valladolid.html; www.Revistaviajeros.es; http://andaluciainformacion.es 


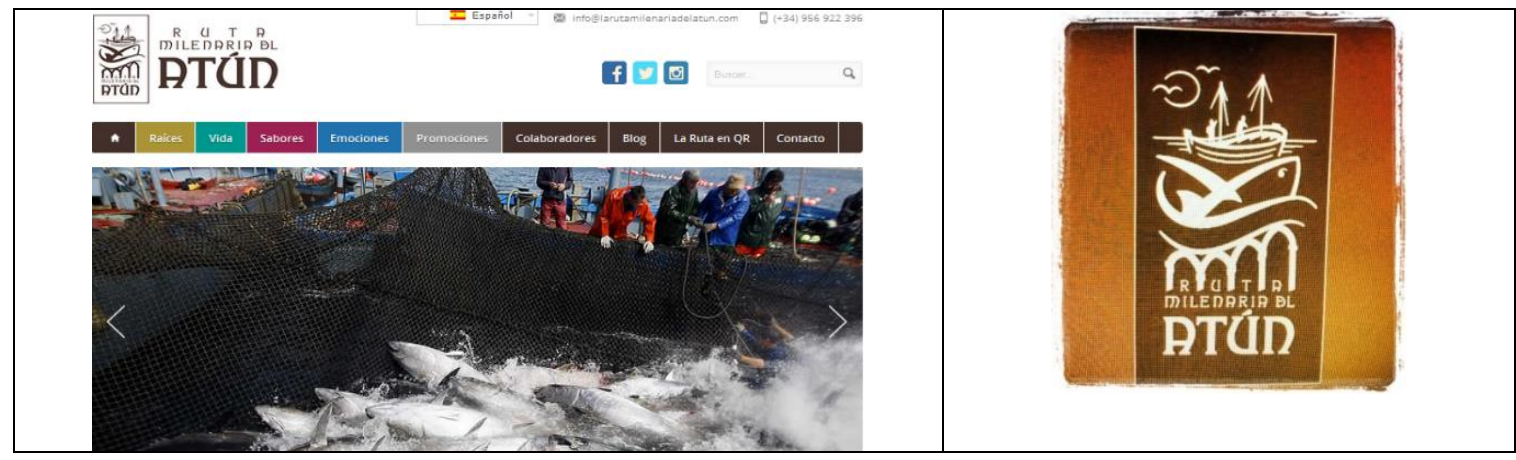

Caso 5: Web oficial e Imagen Corporativa de la Ruta Milenaria del Atún

Fuente: www.larutamilenariadelatun.com; http://bitacoradelahenche.blogspot.com.es/2014/01/la-rutamilenaria-del-atunhttpwww.html

Varios estudios muestran que el $52 \%$ de los usuarios de Facebook aseguran que las fotos de sus amigos les inspiran a la hora de decidir el destino vacacional (Four Pillars Hotels, 2016), por ello el uso de la red social Facebook y el feed back de dicha cuenta con los seguidores de la Ruta Milenaria del Atún, es un instrumento relevante en su comunicación son su mercado objetivo, además de la presencia en redes como Instagram (esencial en el sector turístico por la cantidad de imágenes generadas de los destinos) y Twitter (Véase Caso 6).

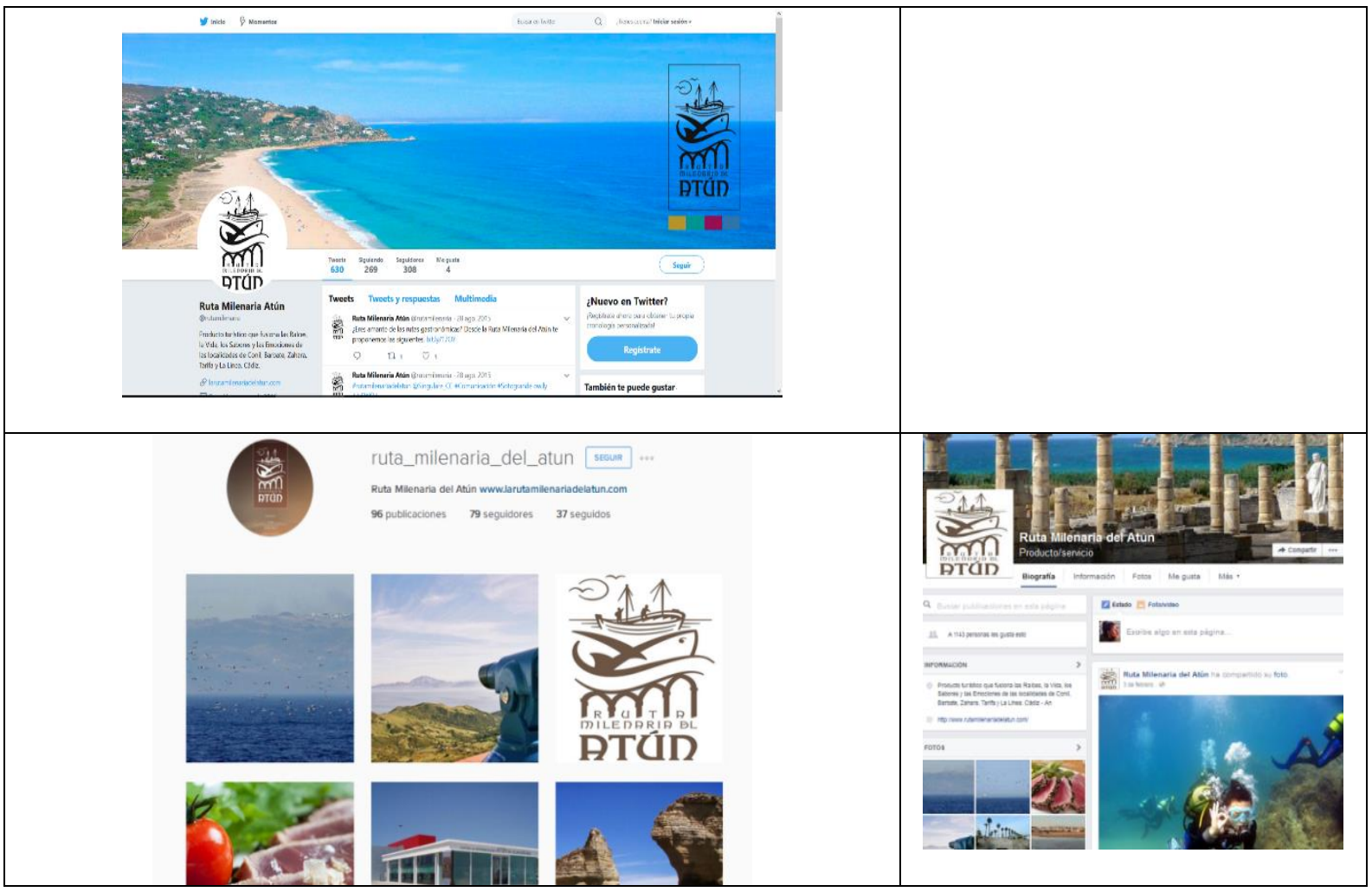

Caso 6: Difusión Online: Perfiles de Twitter, Instagram y Facebook de la Ruta Milenaria del Atún Fuente: www.larutamilenariadelatun.com;

\section{CONCLUSIONES}

De acuerdo con la aproximación conceptual y la revisión de la literatura realizada en este trabajo, es posible concluir que, el producto Ruta Milenaria del Atún supone una oferta turística a explotar como oferentes de "experiencias", para un nicho de mercado cada vez más exigente en busca de la "experiencia turística".

Tal como sugieren numerosos autores, la industria turística debe buscar alternativas que proporcionen una respuesta a una demanda cada vez más exigente y segmentada, que busca experiencias en los destinos turísticos (Rey, 2017; Moral y Alles, 2012; Barkoza, 2013; Cuenca y Prat ,2012; Ninimen, March y Buhalis, 2006; Mill y Morrison, 2002). 
En la actualidad, el turismo gastronómico y cultural adquiere gran relevancia y los destinos de experiencia se posicionan como espacios turísticos (Mascarenhas y Gândara, 2010). Al integrar aspectos como la cultura y las tradiciones de las gentes del lugar, el turista se siente inmerso en su forma de vida local (Mascarenhas y Gândara, 2010) y obtiene una imagen positiva del destino visitado.

En este contexto se ha estimado conveniente la creación de un nuevo producto turístico, La Ruta Milenaria del Atún, que se adapte a las nuevas exigencias de experiencias turísticas por parte de la demanda turística.

La experiencia se ha convertido en objeto esencial del viaje y el cliente siente cada vez más la necesidad de experimentar un destino, pero son pocos los estudios analizan la experiencia sensorial en las áreas cuyo producto es el turismo de Sol y Playa y, menos aún, en referencia a las actividades de ocio alternativas al mismo.

Este trabajo viene a analizar ese concepto de turismo experiencial con La Ruta Milenaria del Atún como base del producto turístico y como respuesta a la actual demanda hacia la búsqueda de experiencias en los destinos que visitan.

El presente trabajo contribuye a la literatura del turismo experiencial integrando las nuevas estrategias de comunicación como instrumento para contactar con ese turista experiencial. En consonancia, se desarrolla un análisis de un producto/recurso concreto, como es la Ruta Milenaria del Atún y se analizan las estrategias de diseño de producto (oferta de experiencias) y de comunicación de su oferta de ocio experiencial, a través, especialmente, de las redes sociales y las páginas Web.

Este estudio no sólo arroja luz sobre los cambios producidos en la demanda turística, sino también contribuye a comprender algunas estrategias que los destinos con estacionalidad acusada por la oferta de turismo de Sol y Playa están llevando a cabo con el fin de reducir los riesgos de la estacionalidad y masificación turística.

Existen nuevos grupos de turistas que buscan experiencias únicas y actividades "locales. Este movimiento del turismo facilita el renacimiento de tradiciones y permite la creación de empleos y nuevas oportunidades para los negocios tradicionales, como muestra el presente caso de estudio centrado en el lanzamiento del producto Ruta Milenaria del Atún.

El trabajo añade a los estudios de turismo experiencial, el análisis de los nuevos instrumentos de comunicación para generar interacción con el nuevo turista en busca de experiencias locales en los destinos que visita, especialmente en el inicio del ciclo de vida del producto/destino turístico.

El diagnóstico revela que el turismo es sin lugar a dudas uno de los pilares de la economía de las localidades integrantes de la Ruta Milenaria del Atún, pero su trascendencia o repercusión va más allá de lo meramente material o económico. Este hecho hace que merezca la pena aunar esfuerzos en diseñar estrategias que fomenten su desarrollo sostenible, es decir, que atienda no sólo las necesidades de las generaciones presentes (turistas, comunidades receptoras, empresariado, personas empleadas, Administraciones), sino también de las generaciones futuras.

Finalmente, no se ha de olvidar que estamos ante un producto turístico en las primeras fases de su ciclo de vida y la mayor parte de la inversión se ha realizado en el diseño del mismo. Por ello, es aún pronto para realizar un estudio en profundidad del uso de instrumentos de comunicación y las redes sociales para relacionarse con el consumidor de turismo experiencial.

Para concluir, el trabajo es diferente a los estudios anteriores por varias razones. En primer lugar, se integran como elementos de estudio del turismo experiencial a nuevos productos turísticos basados en la gastronomía y en las tradiciones locales como recurso turístico; en segundo lugar, se considera la interacción comercial y otro tipo de actividades productivas en las zonas turísticas, en concreto, las relaciones sociales y la colaboración entre pequeños emprendedores del sector turístico, asociaciones locales y las instituciones encargadas de la gestión y desarrollo inicial del Proyecto Ruta Milenaria del Atún, apenas analizada en la literatura. Por ejemplo, la colaboración entre instituciones públicas (Grupo de Desarrollo Cádiz-El Estrecho y Consejería de Agricultura, Pesca y Desarrollo Rural de la Junta de Andalucía), culturales (Museo de Atún La Chanca) y empresariales (empresas de salazones de la zona) y de hostelería, comercio y turismo (hoteles, restaurantes, empresas de actividades de ocio) para promover experiencias culturales y turismo experiencial en torno al Atún y la Almadraba.

La investigación realizada podría ampliarse otras zonas costeras españolas que están trabajando, igualmente, con la cultura, el pequeño comercio y las tradiciones como recursos de turismo experiencial, para combatir la estacionalidad del turismo de sol y playa. Por otra parte, el turismo experiencial e iniciativas como las descritas en el trabajo, podrían ser igualmente replicables en destinos de interior, que ofrecen turismo cultural y urbano o turismo rural o de naturaleza.

La principal limitación de esta investigación es que propone la creación de una ruta y el análisis se ha realizado en las primeras fases de ciclo de vida del producto, en las cuales la mayor inversión se ha realizado en el diseño 
de los recursos que componen los productos turísticos ofertados y en dar a conocer la marca/destino Ruta Milenaria del Atún. Sería conveniente realizar estudios en diferentes años para analizar la repercusión sobre la economía, la sociedad y la estacionalidad que ha tenido la creación de dicha ruta, conocer cómo evoluciona la red de colaboración entre la Administración pública y la pequeña empresa privada del sector turístico o cómo afecta la marca Ruta Milenaria del Atún en la comercialización turística nacional e internacional.

\section{BIBLIOGRAFIA}

AGAPITO, D., MENDES, J. y VALLE, P. (2013): "Exploring the conceptualization of the sensory dimension of tourist experiences", Journal of Destination Marketing \& Management 2(2), pp.62-73.

AGAPITO, D., VALLE, P. y MENDES, J. (2014): "The sensory dimension of tourist experiences: Capturing meaningful sensory-based themes in Southwest Portugal”, Tourism Management, 42, pp.224-237.

BALLANTYNE, R., PACKER, J. y SUTHERLAND, L. A. (2011): "Visitors' memories of wildlife tourism: Implications for the design of powerful interpretive experiences", Tourism Management, 32(4), pp. 770-779.

BELTRÁN, M.A. y PARRA, M.C. (2017): "Perfiles turísticos en función de las motivaciones para viajar", Cuadernos de Turismo, 39, Enero-Junio, pp.41-65.

BIGNE, E., FONT, X. y ANDREU, L. (2000): Marketing de destinos turísticos, ESIC Editorial, Madrid.

BUTLER, R. (1980): "The Concept of a Tourist Area Cycle of Evolution: Implications for Management of Resources", Canadian Geographer, vol.24, no 1, pp. 5-12.

BUTLER, R. (2004): "Geographical research on tourism, recreation and leisure: origins, eras and directions", Tourism Geographies: An International journal of tourism space, place and enviroment, 6 (2), pp. 143162.

CAMISÓN, C. (1998): "Dirección estratégica de empresas y destinos turísticos: Balance del estado de la cuestión y propuesta de un marco integrador orientado a la competitividad", VIII Congreso Nacional de ACEDE. "Empresa y Economía Institucional". Las Palmas Gran Canaria, 20 al 22 de Septiembre, pp. 49-85.

CASTAÑO, M. (2015): "Destinos inteligentes para el turista del siglo XXI con Big Data y 'smart cities". EI Mundo. Disponible en: http://www.elmundo.es/economia/2015/02/27/54ef738be2704e30568b4572.html (Último acceso: 18 mayo 2017).

CROSS, R. y PARKER, A. (2004): The hidden power of social networks. Cambridge, MA: Harvard Business School Press.

CUENCA, M. y PRAT, A. (2012): "Ocio experiencial: antecedentes y características". Arbor. Ciencia, Pensamiento y Cultura, vol. 188, ํㅡㄴ 756, pp. 265-281.

DEAN, J. (1950): "Princing Policies for New Products", Harvard Business Review, vol. 28, nº 6, (Noviembre/Diciembre), pp. 45-54.

DE LA BALLINA, F.J. (2017): Marketing turístico aplicado. Libros profesionales de empresa, ESIC Business Marketing School, Madrid.

GARCÍA, B. (2011): Marketing del turismo rural, Editorial ESIC-Pirámide, Madrid.

GARCÍA, B., REINARES E. y ARMELINI G. (2013): "Ciclo de vida de los destinos turísticos y estrategias de comunicación: los casos de España y Chile", $A D$ Research, vol 7, no 7, pp.76-93.

GARCÍA, B. (2016): Turismo experiencial. Estrategias comerciales de los Mercados de Abastos de Madrid. Paper, XXX AEDEM Annual Meeting Las Palmas de Gran Canaria.

GRETZEL, U. Y YOO, K. H. (2008): Use and impact of online travel reviews. En O'Connors, P.; Hopken, W., y Gretzel, U. (ed). Information and communication technologies in tourism, 35-46. Springer Vienna.

HINOJOSA, V. (2016): "Cinco tendencias que cambian las reglas del juego del sector hotelero en 2016". Hosteltur. Disponible en: https://www.hosteltur.com/114851 cinco-tendencias-cambian-reglas-juego-sectorhotelero-2016.html (Último acceso: 15 mayo 2017).

HOSANY, S. y WITHAM, M. (2010): "Dimensions of Cruisers Experiences, Satisfaction, and Intention to Recommend”, Journal of Travel Research 49(3), pp.351-364.

HUERTAS, A. (2008): Aplicación de la Web 2.0 a los destinos turísticos. Implantación y diferencias. Paper IX Congreso Nacional "Turismo y Tecnologías de la Información y Comunicaciones. Turitec 2008”, Málaga.

JENSEN, R. (1999): The dream society, McGraw-Hill, NYC

KASTENHOLZ, E., CARNEIRO, M. J. y MARQUES, C. (2012): Marketing the rural tourism experience. 247-264. Strategic Marketing in Tourism Services, Emerald Tsiotsou e Goldsmith, Bingley, UK. 
KOTLER, P. (2003): Mercadotecnia de localidades: como atraer inversiones, industrias y turismo a ciudades, regiones, estado y países. Editorial Diana, México DF.

KOTLER, P. (2008): Principios de Marketing. Editorial Prentice-Hall Diana, México DF.

KOTLER, P. (2018): Marketing 3.0. Editorial LID, Mexico DF.

MACIAS J.I. y GARCÍA A. (2012): "Historias y Leyendas en la Costa de Trafalgar". Asociación para el Desarrollo Rural del Litoral de la Janda.

MACKAY, K.Y. y VOGT, C. (2012): "Information Thecnology in everyday and vacation context". Annals of Tourism Research, 39(3), pp.1380-1401.

MANSFELD, Y. (1992): "From motivation to actual travel”. Annals of Tourism Research, 19(3), pp. 399419

MASCARENHAS R.G. y GÂNDARA, J.M. (2010): "Producción y transformación territorial: la gastronomía como atractivo turístico", Estudios y perspectivas en turismo, 19 (5), pp. 776-791.

MILL, R. C. y MORRISON, A. M. (2002): The tourism system. Dubuque, lowa, Kendall.

MORAL, M. M. y ALLES, M. T. F. (2012): "Nuevas tendencias del marketing: el marketing experiencial”. Entelequia: revista interdisciplinar, 14, pp. 237-251.

MORGAN, M. y XU, F. (2009): "Student Travel Experiences: Memories and Dreams", Journal of Hospitality Marketing \& Management 18(2), pp.216.

NAIL, J. (2005): "What's the Buzz on Worth of Mouth Marketing? Social computer and consumer control put momentum into viral Darketing". en: http://www.forrester.com/Research/Document/Excerpt/0.7211.36916.00.html (Último acceso: 12 diciembre 2016).

NIININEN, O., MARCH, R. y BUHALIS, D. (2006): Consumer centric tourism marketing. In D. Buhalis and C. Costa (Eds), Tourism management dynamics: trends, management and tools. Butterworth Heinemann, Amsterdam, London.

PINE, B. y GILMOURE, J (1998), "Welcome to the Experience Economy", Harvard Business Review 76(4), pp. 97-105.

O'REILLY, T. (2007): "What Is Web 2.0: Design Patterns and Business Models for the Next Generation of Software", International Journal of Digital Economics, No. 65 (March 2007), pp. 17-37.

RICHARDS, G. (2004): “¿Nuevos caminos para el turismo cultural? “, Interacció. Barcelona, Centro de Estudios Culturales CERC, pp. 1-15. Disponible en www.diba.es/cerc/arxinterac04/arcem1/richards/dipbarcelona (Ultimo acceso: 15 diciembre 2016).

RICHARDS, G. (2011): "Creativity and tourism: The state of the art", Annals of Tourism Research, Vol. 38 (4), pp. 1225-1253.

REY MORENO, M. (2017): Marketing Turístico: Fundamentos y Dirección, Editorial Pirámide, Madrid.

SCHMITT, B.H. (2003): Consumer experience management: a revolutionary approach to connecting with your customers. Jhon Willey and Sons, New York.

SHEDROFF, N. (2001): Experience design. New Riders Publishing, Indianapolis.

SERRA CANTALLOPS, A. (2011): Marketing Turístico, Editorial ESIC-Pirámide, Madrid.

THEODOSIOU, M. y KATSIKEA, E. (2012): "Antecedents and performance of electronic business adoption in the hotel industry". European Journal of Marketing, Vol 46, pp. 258-283.

\section{WEBGRAFIA}

ANDALUCIA INFORMACIÓN. Recuperado en febrero 2016 http://andaluciainformacion.es/andalucia/590776/la-ruta-del-atun-de-conil-cumple-20-anos/

BARKOZA, J. P. Recuperado en marzo 2016.https://www.youtube.com/watch?v=Vr_humAGAS4

BITACORADELAHENCHE. Recuperado en marzo 2016. http://bitacoradelahenche.blogspot.com.es

DIARIO DE CADIZ. Recuperado en febrero 2016. http://www.diariodecadiz.es; http://www.diariodecadiz.es/article/provincia/1910381/la/ruta/milenaria/atun/se/promociona/intur/valladolid.html

EUROPA PRESS. Recuperado en enero 2016. http://www.europapress.es/andalucia/turismo00476/noticia-cadiz-turismo-fitur-ruta-milenaria-atun-presenta-ronqueo-atun-rojo-salvaje-200-kilos$\underline{20140122161824 . h t m l}$ 
FOUR PILLAR HOTELS. Recuperado en 2016. https://www.phcompany.com/http://www.hmobile.es/2015/06/15/el-impacto-de-las-redes-sociales-en-el-sectorhotelero/.

GUIA DE CADIZ. Recuperado en marzo 2016. http://www.guiadecadiz.com/es/agenda/mayo/2015/xixruta-del-atun-conil

GRUPO DE DESARROLLO PESQUERO CADIZ EL ESTRECHO. Recuperado en abril 2016. http://gdpcadizestrecho.blogspot.com.es/

INE. Recuperado en marzo 2016. http://www.ine.es/

IV PACTO ANDALUZ PARA EL TURISMO 2013. Recuperado en marzo 2016. http://www.juntadeandalucia.es/export/drupaljda/IVpacto turismo.pdf

ORGANIZACIÓN MUNDIAL DEL TURISMO. Recuperado en marzo 2016. www.unwto.org

PATRONATO PROVINCIAL DE TURISMO DE CÁDIZ. Recuperado en enero 2016. www.dipucadiz.es/patronatoturismocadiz

REVISTA VIAJEROS. Recuperado en junio 2016. www.revistaviajeros.es

RUTA MILENARIA DEL ATUN. Recuperado en junio 2016. www.larutamilenariadelatun.com

TURISMO DE CADIZ. Recuperado en marzo 2016. http://www.cadizturismo.com/; http://www.cadizturismo.com/gastronomia/rutas-gastronomicas/

WORLD YOUTH STUDENT AND EDUCATIONAL. Recuperado en mayo de 2016. https://www.wysetc.org 